\title{
TRANSLOCATION
}

\section{AS A MEANS OF PRESERVING WILD ANIMALS}

\author{
By A. M. HARTHOORN, F.R.C.V.S. \\ Department of Physiology, Faculty of Veterinary Science \\ University College of East Africa
}

By translocation is meant the transfer of wild animals from one area to another. The term may be used in the positive sense of introducing animals into an area, for instance to enhance the value of a reserve by re-introducing species that have been exterminated there, or in the negative sense of removing them from conflict with human interests as an alternative to their destruction.

In its simpler form, translocation may consist of driving wild animals a few miles to another area and keeping them from re-entering their old one. This method, usually accompanied by fencing, is an important means of preventing damage to forestry or agriculture and will become increasingly important. More complicated is the large scale movement of numbers of animals over long distances. This entails not only catching, handling and transporting the animals but involves a number of environmental problems.

Animals may be caught in a number of ways depending on their size and behaviour. In East Africa we are principally concerned with the larger ungulates and to some extent with the carnivores.

For this purpose of movement, animals ranging in size from young elephants downwards, have been caught since very early times, often in ways that are still applicable, but modern immobilizing techniques are making the movement of wild animals easier, cheaper and more widespread, bringing it into the province of the maintenance of parks and reserves.

\section{The NeEd for Translocation}

Many species of African animals are now sufficiently rare to render their destruction wrong on scientific and ecological principles. Some of these exist only outside game reserves and parks. Others are represented in these special areas but in small and possibly not stable numbers. Some animals, such as the black rhinoceros, are not yet rare but are dwindling rapidly. The time has come when these animals should not only receive complete protection from hunting, and as great a measure of protection as is possible from poaching, but should also be preserved even when their presence conflicts with agrarian or social interests. Often the only remedy is to remove the animals to an area where they can exist without coming into conflict with their surroundings. This is seldom a simple matter and is likely to involve various ecological questions such as (i) Is the area far enough from the animal's former haunts, or sufficiently separated by geographical boundaries, to prevent a return? (ii) Will the vegetation in the area stand the introduction of more individuals ? (iii) Did this animal exist there in former times, and is the vegetation, mineral content and so 
forth, suitable for it? (iv) Are there factors in the environment that will militate against the survival of the newcomers, such as a lower or higher altitude, a different climate, or unaccustomed predators or diseases ? (v) Will the animals be able to throw off the effects of their journey, including tranquillizing drugs, and adapt themselves to their new surroundings quickly enough to prevent them from falling an easy prey to its detrimental influences.

Animals may safely be moved a certain distance immediately after capture. Although this distance, which varies with different species, has been considerably extended by modern techniques, its limits are still fairly rigid. Where they are likely to be exceeded, the animals to be moved must first be kept in a temporary holding ground so that they may be tamed before travel. This ensures that the animal suffers less apprehension from being handled and possibly crated ; that he is properly hydrated and has recovered from the trauma and exhaustion of being caught; that there has been an opportunity to remove some of his parasites such as trypanosomes or worms, which though normally innocuous, may jeopardize his existence under adverse conditions; that he is able and willing to eat artificial food and to eat and drink in a crate or other confinement. Most of the large herbivores suffer from one form or another of shipping fever, and relatively minor disturbances in their normal way of life will precipitate a crisis in their internal bacterial balances, or metabolic environments.

Decentralisation of small herds of rare animals.

Even where these small remnants are not in immediate danger it may be useful to move some of them, for fear that disease or natural calamity should wipe out the nucleus. Movement may be especially desirable where numbers are increasing in the original area and a reduction can be contemplated-as in the case of the Hunter's hartebeest and, in some areas, the white or square-lipped rhinoceros. Usually places are known where such animals once existed, although that does not necessarily mean that other animals of the same species will take readily to being transported there. Differences in rainfall, altitude, humidity and temperature may be of little account to animals which have become adapted to them in the course of years, yet be fatal to an animal that is moved there overnight. The problem may be lessened by the transport of the younger and more resilient members, but on the other hand, these may be more susceptible to factors such as predation, for it is the older animals that are able to keep cohesion in a herd or group or give the necessary leadership.

With some species, especially the white rhinoceros, social behaviour may preclude breeding in groups of less than a certain number, as yet undefined. This means that a group of animals larger than prudence would seem to dictate, may have to be risked in order to pioneer a new place.

The transfer of animals from one reserve to another.

Animals may have to be moved from one reserve to another for a number of other reasons - an important one being the introduction of new blood to isolated herds. Reserves under whatever title, are decreasing in size. 


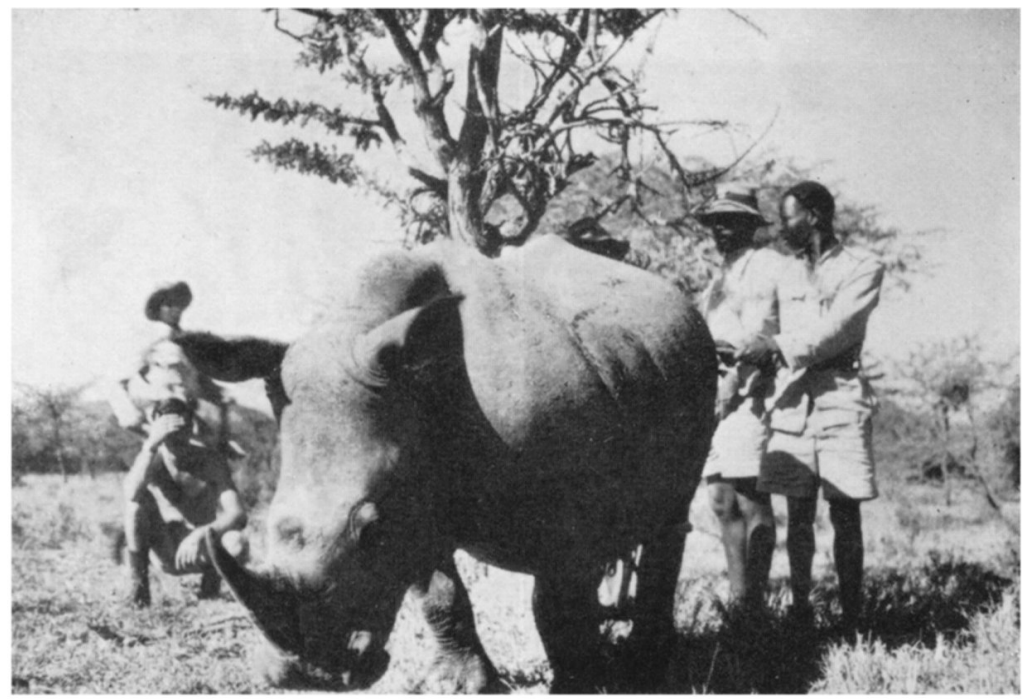

Photo: A. M. Harthoorn.

Translocation of a white rhinoceros after the use of a modern narcotic mixture. $\mathrm{He}$ is about to walk calmly into a crate.

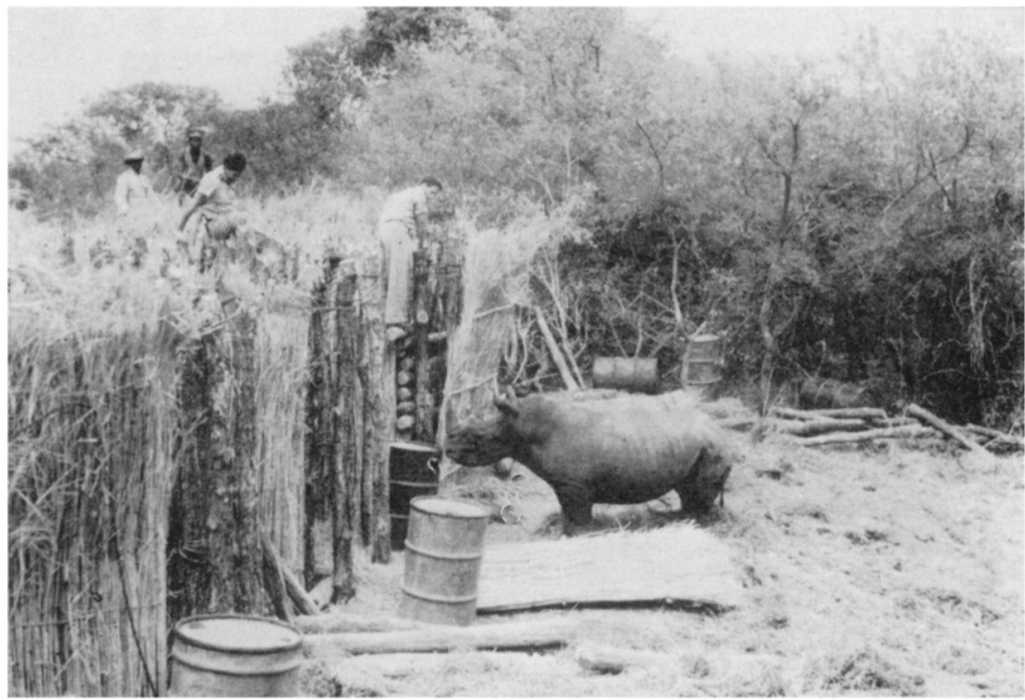

Photo: N. Steele and I. Player.

A black rhinoceros after being moved and released in the Kruger National Park. 

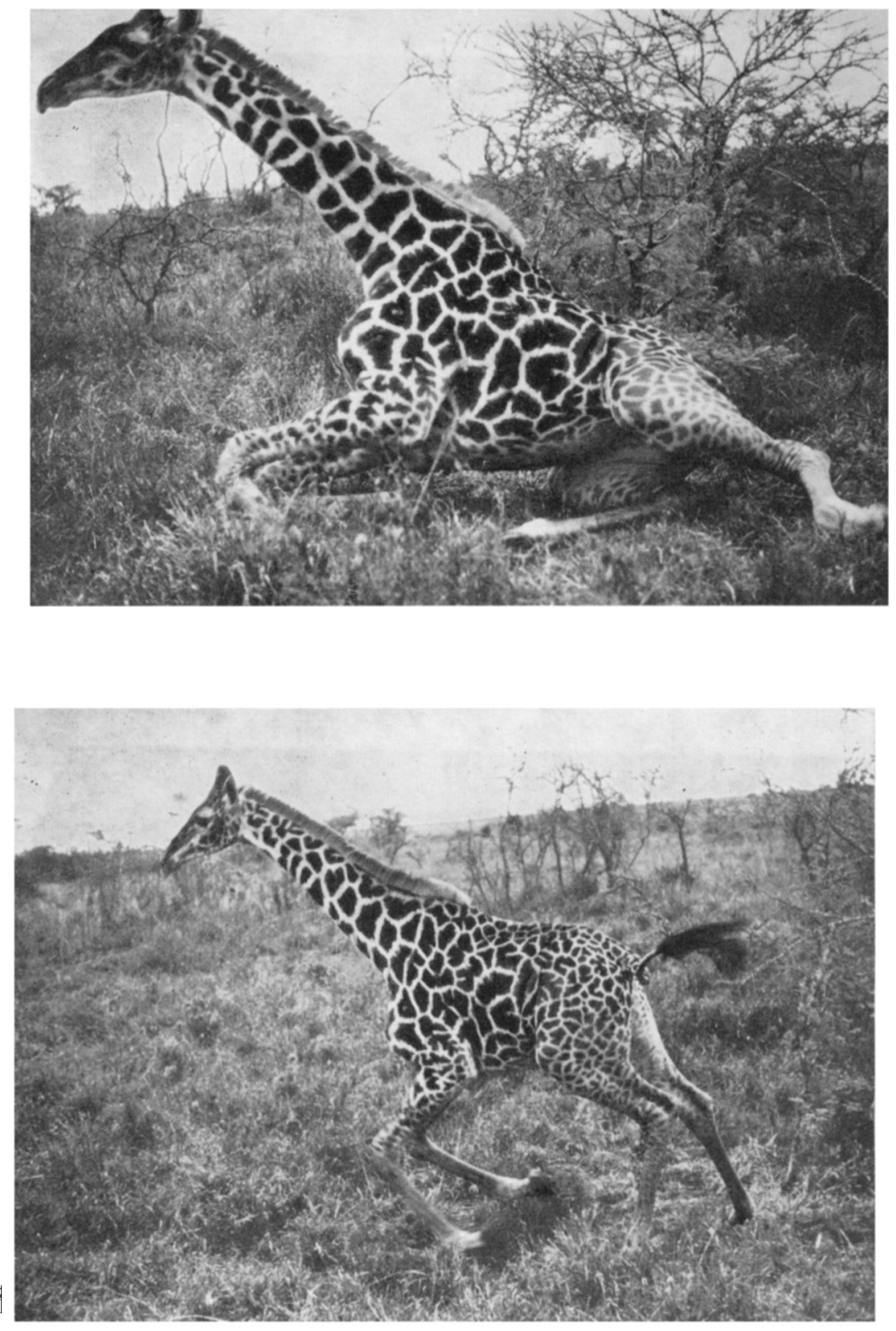

Photos: A. M. Harthoorn.

TRANSLOCATION OF A GIRAFFE Above-Recovering from the drug. Below-Moving off. 
Where a strict reserve has decreased but the remains of its former area has been converted to a controlled hunting area, the question of homozygocity or inbreeding should not arise. Other reserves, however, are either small from their inception or have been reduced in size. Or else a herd in a small reserve, once in free exchange with the surrounding countryside, has been cut off by agriculture or fencing, from other groups. The herds of animals isolated in this way may be small. A nucleus of animals introduced into a reserve or park may be smaller still.

There is no scope here for a discussion on genetics, but it can be said, without fear of contradiction that, if the number of animals falls below a certain level or is never built up above a certain level, inbreeding will result. The threshold at which this occurs probably differs not only with the species but with the particular race. In principle it will occur eventually with all animals in small and restricted groups. Although under carefully controlled conditions inbreeding can be beneficial, without such control its effects may be predominantly bad. Eventually a recessive factor such as sterility may become dominant and result in the depletion and eventual disappearance of the herds in question.

All small reserves or parks should keep their animals under careful observation. When changes occur in the average body weight, appearance, annual increment, or susceptibility to disease, the cause must be found. In many cases it will be found to be nutritional, either associated with gross lack of food, minerals or trace elements. In others it may be due to inexpert cropping such as the persistent shooting of the best herd bulls. If it is found to be due to inbreeding, immediate steps should be taken to acquire new stock.

In theory the introduction of one good new herd bull ought to make a considerable difference, especially if he is replaced by another after one crop of calves. In practice it may be difficult to get a new animal accepted by the herd and much effort will have to be expended to ensure the success of the project. Any animal introduced in this way should of course be clearly and permanently marked.

In some instances the introduction of young male stock may be sufficient, relying upon their superior vigour to ensure an active part in breeding. This may have to be accompanied by a degree of control of the existing young male crop.

In Uganda some of the indigenous antelopes such as oryx, kudu, and to a certain extent giraffe, exist only in outlying districts. The introduction is contemplated of small numbers of these into other places such as Entebbe, principally to create an interest in them and thus in their preservation. In a small way this has been done already-the movement of kob antelope for example.

\section{Disease.}

In the parks and reserves in East Africa no control is exercised at present of the various enzootic and epizootic diseases that occur among wild animals. This lack of control is permissible because most of the reserves are large enough for such diseases to "burn themselves out" 
and thus to rely on a natural immunity developing in the resident stock. Fortunately no direct threat has yet been offered to groups of rare animals.

The borders of the parks and reserves are mostly open to the passage of wild animals, and the onslaught of a disease, for example rinderpest, tends to induce an exodus from the focus of infection. Infected animals such as buffalo travel abnormal distances and appear to try to leave the locality. This disperses the disease over a larger area among both wild animals and domestic stock, and results in many of the infected animals being destroyed when measures are taken by local authorities to prevent the spread of the disease. But it increases the chance of pockets of healthy animals remaining out of contact with the disease.

Rinderpest is taken as an example because it is one of the few diseases that takes heavy toll of wild animals even under natural conditions. Perhaps it is not the best example because it was introduced into Africa only at the end of the last century, and the indigenous wild animals are still highly susceptible. We may suppose that in the course of time, an immunity to rinderpest will develop due either to mutation of the virus to a somewhat less virulent form, or to an immunity developing. Indeed it appears that a degree of immunity exists among some animals already; for when epizootics of various intensity sweep the country, they seem to possess special virulence for one particular species at a time.

The diseases of wild animals are largely unknown and it is therefore very hard to make accurate predictions. Investigation is often extraordinarily difficult. In the Murchison Falls park, Uganda, elephants have been dying for some time of an unknown disease, yet a fresh carcass has never been found and only once has an elephant been seen to die. On that occasion it was only possible to demonstrate that the animal did not die of anthrax.

Vaccination of breeding stock or young stock of wild animals might seem a useless or even frivolous exercise, but the possibility, and above all the techniques, should not be neglected as their use may one day become imperative. In the Queen Elizabeth park a number of adult buffalo were vaccinated, using drug immobilizing methods to render handling possible. It was done to judge the feasibility of catching the buffalo in some quantity and their reaction to injection of the attenuated but living virus.

To catch and vaccinate individual adult wild animals is expensive, and useful only for small numbers of valuable breeding stock, or in an emergency. Other methods might be employed such as driving and corralling of the young and vaccinating them as they go through a shute, or other methods employed for cattle. A great deal of research is needed in this field and it should not be delayed until it becomes urgent.

The vaccination of translocated animals should be a routine measure. It may be against normal enzootic diseases with which the captured animals are likely to go down due to trauma, the exhaustion of capture, or the strain of a change of diet. An example of this is haemorrhagic septicaemia of giraffe, which may cause severe losses unless they are vaccinated on capture. It may be against a disease affecting local livestock, to comply with local quarantine regulations. It may be against diseases which occur in the receiving areas, especially as the vitality of the animals may be lowered by captivity, or by the strange surroundings on release. 
Animals such as the rhinoceros which are resistant to trypanosomiasis may succumb to it if debilitated by capture. Treatment with trypanosomiadal drugs appears to have a salutary effect.

\section{Direct therapeutic and surgical interference.}

This may consist in helping animals that have been trapped, snared or caught in natural hazards and may include the removal of foreign bodies. There have been many cases of help being given to animals that have been snared-for example by shooting through the snare itself-and to large animals such as rhinoceroses, both white and black, which have been caught in pits, by breaking down the side of the pit or by dragging the rhinoceros out by a rope round the hind quarters. Recently, help was given to a giraffe with a snare on its foot after immobilization with a muscle-relaxing drug. Therapeutic interference was also recently attempted, after immobilization, on a lame elephant, but it proved to be suffering from a fracture due to a shot wound. Veterinary treatment has been carried out successfully on black rhinoceroses caught for translocation and found to be suffering from arrows embedded in their flesh. These arrows, carrying a sub-lethal dose of cardiac glycocide, appeared to create traumatised areas but no lasting systemic disturbance.

Where individuals of small communities of rare animals are affected by treatable surgical conditions, destruction is not necessarily the only answer. The possibility of rendering assistance to them in the semi-captivity of small parks and reserves is a pleasing aesthetic concept, especially to the modern sightseer; and reports on such cases are a valuable means of inducing interest in the animals and their surroundings.

\section{Examples of Translocation of Wild Animals}

\section{Kob antelope.}

In June 1959 a dozen female kob antelope and one male were moved from Lugari in Kenya to the African District Council Game Reserve at Meru. As an experiment it was highly instructive, for a number of problems were successfully overcome and a fund of knowledge was acquired which can be put at the service of future translocation exercises.

The antelope were caught by using a muscle-relaxing drug and moved while tranquillized to a holding area. Later they were moved, under the same tranquillizer, into a truck and then 320 miles to the reserve. The fact that no losses were sustained during this long move augurs well for the future and greatly increases the feasibility and prognosis of similar moves.

\section{Black rhinoceros.}

Both the value of the black rhinoceros as a dwindling species as well as moral obligations promoted the rescue of rhinoceroses from islands at the Kariba lake. Using the drug-immobilization method, eight rhinoceros were rescued. Once drugged, the rhinoceros was easily turned on to a skid, moved a short distance overland and pulled on to a raft. 
A new drug combination that allows recovery without recourse to an antidote and with a very much larger safety margin has recently been adapted for white rhinoceros. If it can be applied to the capture of black rhinoceros, it should simplify the method considerably, making it usable by relatively untrained personnel and greatly reducing the danger of mortality.

\section{White or square-lipped rhinoceros.}

Early in 1961 a number of white rhinoceroses were captured in the West Madi area of Uganda for movement to the Murchison Falls National Park. Half a dozen calves were roped without loss but adults proved less easy to rope and were more susceptible to injury. Successful drug immobilization of even adult males of the southern white rhinoceros has been achieved. The drug renders the animals extraordinarily tractable, so that on recovery (expedited by the administration of small quantities of antidote) they will walk into crates with almost no coercion.

This drug-capture method may greatly facilitate the capture of the large ungulates and enable a complete revision to be made of costs, losses and feasibility of handling of the larger animals.

\section{Giraffe.}

In several areas of East Africa, giraffe are becoming an increasing problem to farmers and cultivators, through their predilection for certain crops and their damage to fences. Apart from its comparative rarity and its beauty, the giraffe occupies, with the okapi, a unique place in the animal world, and the destruction of these animals is repellent.

During a small pilot translocation exercise in Uganda, it was discovered that giraffes can be caught by the drug technique with virtually no mortality, and that even a fully grown giraffe may be readily moved into a truck by hand or winch with the help of only a few men. Giraffes are readily quietened by the injection of only a very small amount of tranquillizer and settle down to life in an enclosure almost from the moment they are put in.

Much is still to be learned about the long-distance transportation of giraffe. Reports from South Africa indicate that frequent stops for rest are essential to save them from death by nervous exhaustion.

Giraffe are readily fenced by a structure not much stronger or higher than a cattle fence. Unlike antelope and pig they neither jump nor climb through a fence, and only the larger bulls will make a determined effort to break a reinforced top strand of fencing wire. Giraffe are easily driven but tend to retrace their footsteps overnight.

The transport of a gravid female giraffe may not necessarily be injurious. A female was carried on her side over five miles or so of rough country, undergoing physiological measurement of blood and respiratory gases. Three days later in captivity she gave birth to a normal calf at term. The calf was nursed and appeared to receive full attention. 


\section{Techniques for Capture and Driving without Capture}
(A) Drug immobilization.
(B) Chasing and roping.
(C) Driving into shutes and corrals.
(D) Driving without capture.
(E) Trapping.

\section{(A) Drug immobilization.}

This method of capture is effected by a projectile syringe, propelled in various ways and capable of injecting a drug or drug mixture which acts on the central and the peripheral nervous systems. It is of recent invention, and as it is still in the experimental stage the mortality suffered during the assay of various drugs should not be compared unconditionally with the mortality resulting by the use of older methods. It is reasonably certain that in the course of the next year or two, rapid advances will be made in the elucidation of suitable drugs and of techniques in their administration. Similar refinements in the older techniques are not so likely. All the methods of capture listed above will probably continue to have a place in the handling and transport of wild animals.

The advantages that should attend the evolution of sound means of capture by drug immobilization are as follows : (i) The cost of capturing individual animals will be greatly reduced, mainly because it will seldom be necessary to chase them with motors. (ii) The equipment needed is small and light and may be carried at all times by wardens and rangers. (iii) Individual animals may be taken with almost no disturbance to other animals in the same herd or area. (iv) Animals in advanced pregnancy may be caught, using drugs with apparently no harm to dam or conceptus. (v) The distress to the animal from being caught by the drug technique is probably far less than that caused by chasing and roping. (vi) The technique, when properly established, can be readily learnt by those entrusted with the care of animals and thus become more widely available.

\section{(B) Chasing and roping.}

This method is very suitable for the capture of particularly wary animals, but it does bring in the added expense of damage to vehicles, especially on rough ground ; for there are many areas in Africa where the terrain makes rapid driving difficult and dangerous.

Some plains antelope such as eland are difficult to approach near enough to allow the injection by a dart or syringe with accuracy and consistency, whereas they are easily overtaken by car. A combination of methods may be used whereby the animal is chased by car until close enough to fire a dart.

The use of vehicles not only for chasing and roping, but also for catching animals by drug techniques may be mandatory in some kinds of country. In bush areas where they are hunted or poached, animals such as the black rhinoceros are difficult to follow up except by using a bush vehicle. 
Tracking methods are not sufficiently sure to be able to spoor the animal rapidly and with certainty. Horses have been used with complete success for following rhinocersos but their use is strictly limited by the presence of tsetse fly in most rhinoceros areas.

(C) Driving into shutes and corrals.

This method must be developed as it is the only way by which whole herds of antelope can be captured rapidly and with small expense. The method has been considerably used in South Africa for cropping antelope on farm land and in at least one case, for translocation-bontebok from Bredasdorp to Swellendam. How well the method would work on completely wild antelope in bush country has yet to be discovered. Up till now attempts to drive antelope such as kob into nets have failed, but in Uganda kob seem to react well to driving into natural gullies. The expense of the initial outlay in construction of the corral and wings precludes the experiments that are desirable. An "endless" circular shute at the apex of the wings would discourage the antelope from hurling themselves against the barricades. At Lugari the catching of corralled animals by driving them into a shute at night, with strategically disposed lights, has been shown to be feasible. Feeding of tranquillizers in food or water to the corralled animals was not attempted, but is a logical evolution. The possibility of using this method for the development of other forms of management of wild animals, such as for vaccination, is an added incentive to experiment.

\section{(D) Driving without capture.}

Driving animals from one area to another has failed in East Africa, because it has not been possible to prevent their return. A concerted attempt was made some years ago to drive Rothschild's giraffe from farmland in the Kitale-Kapenguria area into West Suk. Horses were used, and the giraffe successfully driven, although not down the escarpment as was planned. But they returned immediately.

Driving of game animals is probably only feasible in conjunction with fencing. In Natal, eland were successfully driven through a quarter-mile gap in a fence at Giants Castle, but at walking pace over a number of days with the drivers approaching no closer than several hundred yards.

\section{(E) Trapping.}

Trapping in boxes or similar devices will probably remain the only way to catch carnivores, both large and small. It provides an alternative to shooting, poisoning or foot-trapping those that raid cattle bomas or chicken houses or take up residence near towns. Ingenious traps made of resilient material virtually prevent self-inflicted damage. The release of these animals after translocation is fraught with some difficulty because of their tendency to return promptly to their former haunts.

Some antelope, such as impala, are readily caught at night by artificial light. Where this is possible, it provides one of the most simple means of catching the smaller ungulates. 


\section{TRANSPORTATION}

The methods of transporting the captured animals differ according to species and sex, numbers, the distance to be travelled, the type of country and the speed with which the animals can be collected.

Small female antelopes of species in which only the males have horns are very easily transported after being tranquillized and released into the darkened interior of a lorry. The motion induces them to lie down with their legs folded beneath them. Kob antelope took to this form of transport astoundingly well, after the intramuscular administration of one milligramme per pound body weight of chlorpromazine hydrochloride. The kind of tranquillizer appears to be very important as a mean must be found between tranquillization in the medical sense, and a soporific that would induce the recipient to go to sleep and lie down on its side. Ruminants must be kept on their briskets, for when lying on their sides they tend to die rapidly from asphyxiation induced by tympany. In cold regions such as the Kenya Highlands hypothermia is an important side effect and overdosage of chlorpromazine must be guarded against, especially at night.

Young male antelopes have been transported with females after the extreme half inch of their horns has been removed and the ends covered with multiple strips of electroplast.

The transportation of either horned or aggressive animals under conditions of individual freedom cannot be contemplated. Large animals such as rhinoceros limit by their size the numbers that can be carried. The black rhinoceros appears to stand transport while tied, and on his side, surprisingly well for as long as five to six hours, and the white rhinoceros for shorter periods ; but shorter times should be aimed at as a degree of pulmonary hypostasis is inevitable, and may show its deleterious effects only after the expiry of a number of days. Small rhinoceroses may be propped on their brisket by sandbags, but this is not easy as the legs have to remain securely tied. Where a long period of transport is inevitable immediate crating of the rhinoceros is an advantage.

\section{Young Animals.}

The capture and transport of young animals may be mandatory in some cases, principally when very large animals are moved. During the capture of white rhinoceros in West Madi, the young reacted better to catching and were easier to transport. Whether they will stand the same chance of survival as the older ones, or even a better chance, it is as yet too early to say. The translocation of young antelope is probably only possible if a herd structure can be maintained. Similar considerations apply to the transport of the female in advanced pregnancy. Kob antelope near term were caught by the drug-capture method without harm, but they appeared to be more susceptible to predation in the release area than the non-gravid female, or those in early pregnancy.

The transport of gravid females and young would have little disadvantage in the case of large animals such as giraffe that are fairly resistant to predation. It is questionable whether the dams would continue to suckle their young and a test trial on this matter is indicated. Undoubtedly even 
well-grown youngsters continue to take some milk, and deprivation of this source of nourishment, at the same time as other unfavourable factors come into operation, might well lead to fatalities. Experience shows that a small amount of natural milk has a preventative effect against conditions such as enteritis. In the ruminants digestive disturbance pending the adaptation of bacterial flora to the new pabulum, is an almost inevitable result of a sudden change of diet. Probably the ruminant's extraordinary low blood sugar renders it particularly susceptible to nervous exhaustion and collapse from this cause should be guarded against.

If animals are to be moved immediately after being caught, precautions should of course, be taken against as many eventualities as possible. These may include ensuring adequate hydration immediately on capture, the use of rehabilitating drugs such as glucocorticoids, replacement of body salt and sugar, administration of medicaments such as antitrypanosomiadal drugs, soporifics and tranquillizers, adequate temperature control.

\section{Numbers.}

Where only a few antelope are involved quite large distances may be traversed in the back of an open Landrover or light truck, with the animal carefully tied and the head restrained by hand. Four female kob, each held upright by one scout, travelled with good effect and apparent unconcern in the back of a long-based Landrover. If the legs are tied with skill close together using nylon bonds, the chances of occlusion of the circulation and of chafing are remote and a three or four hours' journey appears to be no hardship, especially if the road is smooth.

Wild animals, like domestic animals, appear to acquiesce if rendered completely helpless. Misplaced kindness in allowing excessive play may result in struggling and extensive damage, especially to legs and head.

\section{Holding areas.}

The distance and time of travel will determine whether a holding area should be used. Experience shows that a holding area at the place of capture should be avoided if possible, but that it may be employed with advantage at the release point. Rhinoceros are thought to require taming to train them to eat and drink in captivity and to submit to crating before undertaking a journey of any length, but even tamed rhinoceroses have been known to refuse drink on the road, and a journey of three days with over-drinking after release, has proved fatal. Tranquillization will allow transport in crates immediately after capture. Drinking may be replaced by fluid per rectum, or even by hypodermoclyster.

Wild animals tend to lose condition during the early part of their confinement and may be able better to stand the journey immediately after capture than a week or two later.

The construction of a holding area at the release point ensures better adaptation to the new environment-temperature, food and altitude. It allows recovery from the stupefying effects of a long journey and permits complete recovery from the effects of a long journey and from the effects of tranquillizers. It gives the animals a centre from which to explore their new surroundings. 
Most wild animals seem to show a peculiar attachment to their quarters after even a few days' captivity. If the stockade is opened quietly and sufficiently wide, the animals will probably remain in the vicinity and so be accorded a measure of protection. They are also likely to drift away quietly from the holding area and so retain the opportunity of remaining in contact with each other.

Before release into a new habitat animals subject to predation must be free of drug effects and effects of the journey, for the smallest defect in normal behaviour is apparent to predators which have been seen to follow persistently through a whole herd of its fellows an animal which has recovered from drug immobilization. Adequate hydration before release is essential, for the animal may run speedily away from the water area and be unable to orientate itself sufficiently rapidly in its strange surroundings. Where the herbage differs from that of the original area, a gradual weaning to the new herbage should be attempted, if necessary using an intermediary artificial food such as hay or lucerne.

Roads and tracks.

Whereas newly caught animals will usually lapse into stupor during transport on good roads, they will be stimulated into a new bout of struggling whenever a wheel goes into a hole. Similarly, animals appear to enjoy a ride on a good tar road but become very restive on corrugations. Multiple punctures, a common hazard in thorn country, are a source of long and incalculable delay.

\section{Time taken in collection.}

The speed at which the animals can be collected will influence the type of transport used. Where a dozen antelope can be captured in a few hours in the late afternoon, they may be put into a darkened lorry one by one and the whole lot transported for two or three hundred miles during the night. If, on the other hand, only three or four are caught daily, a holding camp becomes essential.

\section{FINANCE}

The cost of translocation depends principally on the motor mileage used in catching the animal, the distance to its new habitat, the expense of temporary holding grounds and the amount of handling and feeding needed. Animals which are thick on the ground are cheaper than those which are scattered. Fifty miles or more may be run between sighting black rhinoceroses, for example.

Bush mileage in Landrovers should be calculated in the region of Sh. 2 per mile and lorry freight rates at much the same. Antelope are usually best stalked from a vehicle such as a Landrover. As the herds move around, mileages of 30 or more miles are run for every load of two or three animals caught.

When roping is employed for capture, the expense increases with the risk of damage to the vehicle. The larger teams necessary for this operation dictate more or bigger vehicles. Expenses are also increased in proportion to the risk to life and limb. 
Large animals cost more to transport in proportion to their weight. When they are simultaneously fast, strong and aggressive, the vehicle used for the older catching methods has to be not only proportionately powerful but specially adapted. More often than not, two vehicles have to be employed.

Whereas the catching of animals by drug immobilization shows a saving in manpower, vehicles, and ropes, some items must be placed on the debit side. A large one is the price of the projectile syringe but that could be reduced by local manufacture. Other expenses are : drugs (including those in syringes that fail to find their target); tranquillizers; antidote to the muscle relaxant where one is used; carbon-dioxide powerlets if a Capchur gun is used, otherwise cartridges for a powdercharge gun and replacements for a cross-bow. Under capital outlay comes the cost of the syringe projector and possibly the cost of the holding enclosures and sometimes of the vehicle.

Whether the salary of the game warden taking part, and the wages of the game scouts should be included is not always clear. It depends on whether the exercise can be regarded as a normal function of a game department, or a field for which special men have to be recruited.

The expenses, taking all into account, for moving kob antelope, were high and more than the market value of the animals moved. The cost in relation to the permanent and sustained value of an established herd is a different matter.

Undoubtedly the cost of early moves was excessive. In a subsequent one the following economies were made.

The use of a longer range gun considerably cut down mileage. The first gun had to be fired at extreme range with consequent loss of accuracy, and after considerable manoeuvring for position. Greater accuracy resulted in far fewer "wides" and lost syringes. Whenever a syringe missed its target two stakes were immediately placed on the line of fire and the syringe subsequently recovered. A considerable proportion of syringe losses experienced during the kob move were due to syringe failure. A redesigned activating mechanism not only rendered the carriage of the syringe easier, but virtually eliminated failures of injection. Damage to syringes due to mushrooming of the front end was a common occurrence, especially when working with hard-skinned animals such as giraffe, buffalo and rhinoceros. A cushion of polystyrene plastic saved the syringe and allowed it to be used more times. Better syringe projectors have greatly decreased the numbers of "wides". Missed shots have dropped from $90 \%$, registered on one exercise, to almost zero.

Cost of drugs.

Some of the drugs which are useful for the capture of animals are being produced in larger containers and are therefore cheaper than in the form designed for human surgical use.

Finally it must be said that the real cost of catching and transporting animals can only be approximately estimated while the technique is still in its experimental stage. With better techniques the cost of capture is decreasing. 
The money spent on the methods here described should be regarded as expended on research, rather than as expenses to be balanced against the market rate for the animals saved. The figure for a member of a widely distributed and actively increasing species may be taken as the price of its meat and hide. The worth of a herd is considerably more whether considered as a renewable source of protein or for its aesthetic value. The value of an individual of a disappearing species is even more difficult to assess for its significance is not computable.

Note.-This paper in a longer form was presented to the CCTA/IUCN Symposium on the Conservation of Nature and Natural Resources in Modern African States, Arusha, Tanganyika, September 1961. 